\title{
NOVAS MONTAGENS DA HISTÓRIA: UM PARALELO ENTRE FREUD E BENJAMIN
}

Paloma Palacio

\section{RESUMO}

Este artigo pretende ensaiar um paralelo entre o desenvolvimento da psicanálise e do cinema como disparadores de novas imagens da história. Partindo das leituras de Márcio Seligmann-Silva (2006) e Jean-Marie Gagnebin (2009), buscase fazer um gesto arqueológico: aproximar a obra do psicanalista Sigmund Freud à do filósofo e historiador Walter Benjamin como esforços singulares do pensamento moderno em busca de uma nova percepção do tempo.

Palavras-chave: Cinema. Psicanálise. História. Testemunho. Memória.

\section{NEW ASSEMBLIES OF HISTORY: A PARALLEL BETWEEN FREUD AND BENJAMIN}

\begin{abstract}
This article intends to experiment a parallel between the development of psychoanalysis and cinema as triggers of new images of history. Based on the analysis from Márcio Seligmann-Silva (2006) and Jean-Marie Gagnebin (2009), we seek to make an archaeological gesture: approach the work of psychoanalyst Sigmund Freud to the work of philosopher and historian Walter Benjamin, as singular efforts of modern thought in search of a new perception of time.
\end{abstract}

Key Words: Movie theater. Psychoanalysis. Story. A testimony. Memory. 


\section{Introdução}

As obras de Walter Benjamin e Sigmund Freud foram marcadas pela ambiguidade, sinal dos tempos em que viveram. Pertencente à chamada Escola de Frankfurt, Benjamin figurava entre os colegas Theodor Adorno e Max Horkheimer como uma espécie de dissidente. Segundo apontam correspondências da época, seus textos eram incorporados às publicações do Instituto de Pesquisa Social, presidido por Horkheimer, após ferrenho debate entre os três autores e incansáveis revisões ${ }^{1}$. Freud, por sua vez, travou no âmbito da medicina seus próprios embates intelectuais. Até os últimos textos, ele buscava defender a psicanálise de críticas cientificistas, afirmando a validade médica de suas práticas. Ao mesmo tempo, o empirismo radical de seu método o levou a traçar diferenças capitais entre o trabalho sobre o inconsciente e a ciência positiva ${ }^{2}$. O que é mais, os dois autores foram confrontados cada qual à sua maneira com a catástrofe da guerra e do fascismo na Europa, no berço do século $X X$.

Segundo Jean-Marie Gagnebin (2009, 51), a mudez e paralisia das vítimas das grandes guerras produziram uma "reflexão convergente sobre a

\footnotetext{
${ }^{1}$ A respeito disso, ver o artigo de Luciano Gatti, "Correspondências entre Benjamin e Adorno". Revista Limiar. Guarulhos, v. 1, n. 2, jan-jun. 2014. Acesso em: http://www2.unifesp.br/revistas/limiar/pdf-nr2/05_Luciano-Gatti_Correspondencias-entreBenjamin-e-Adorno_Limiar_vol-2_nr-1_1-sem-2014.pdf

${ }^{2}$ No seguinte trecho de Análise terminável e interminável (1937), é possível reconhecer a dualidade de Freud. Ao passo que assume a particularidade do trabalho analítico, insiste no paralelo com a medicina para defender a psicanálise: "Não se pode discutir que analistas, em suas próprias personalidades, não estiveram invariavelmente à altura do padrão de normalidade psíquica para o qual desejam educar seus pacientes. Os opositores da análise quase sempre apontam esse fato com escárnio e o utilizam como argumento para demonstrar a inutilidade dos esforços analíticos. Poderíamos rejeitar essa crítica porque faz exigências injustificáveis. Os analistas são pessoas que aprenderam a praticar uma arte específica; a par disso, pode-se conceder-lhes que são seres humanos como quaisquer outros. Afinal de contas, ninguém sustenta que um médico será incapaz de tratar doenças internas se seus próprios órgãos internos não forem sadios; ao contrário, pode-se argumentar que há certas vantagens no fato de um homem que foi, ele próprio, ameaçado pela tuberculose, se especializar no tratamento de pessoas que sofrem dessa doença. Os casos, porém, não são absolutamente idênticos. Enquanto for capaz de clinicar, um médico que sofre de uma doença dos pulmões ou do coração não se acha em desvantagem para diagnosticar ou tratar queixas internas, ao passo que as condições especiais do trabalho analítico fazem realmente com que os próprios defeitos do analista interfiram em sua efetivação de uma avaliação correta do estadode coisas em seu paciente e em sua reação a elas de maneira útil. É, portanto, razoável esperar de um analista, como parte de suas qualificações, um grau considerável de normalidade e correção mental."
}

Mestranda em Comunicação e Cultura, na linha Tecnologias da Comunicação e Estéticas (ECO-UFRJ) e graduada em Rádio e TV (ECO-UFRJ). Brasileira, Rio de Janeiro - RJ. E-mail: palomapalaciom@gmail.com. 
memória traumática, sobre a experiência do choque". Benjamin ensaiou uma crítica dupla ao desenvolvimento técnico em seu texto $A$ obra de arte na era da reprodutibilidade técnica. Nele celebrava a popularização do cinema e da fotografia como forças produtoras de uma nova percepção humana, por um lado; por outro, creditava isso ao que Gagnebin (idem) chamou de "impossibilidade, para a linguagem cotidiana e para a narração tradicional, de assimilar o choque, o trauma".

Na mesma época, afirma a autora, a neurose traumática de Freud "fere, separa, corta ao sujeito o acesso ao simbólico, em particular à linguagem" (idem). Sendo assim, diante do fracasso dos ideais progressistas que fundamentaram as guerras, os dois pensadores atribuíram-se a tarefa comum de buscar uma forma de conceber a história que desse conta da temporalidade ambígua da memória traumática.

Pretende-se ao longo deste artigo, portanto, traçar um paralelo entre as trajetórias intelectuais singulares de Freud e Benjamin a respeito da memória traumática e seus desdobramentos históricos. Com isso, busca-se cumprir um gesto arqueológico em torno da imbricada relação entre cinema e história no que toca o problema do tempo, herdado da modernidade.

\section{Da clínica à cultura: fundamentando os conceitos de trauma e choque}

Em Além do princípio do prazer, Freud começa defendendo a "neurose traumática" como originária de um "desastre" ou "acidente", cujas características principais são a "surpresa" do ocorrido e as marcas deixadas no corpo do acidentado. Segundo o autor, os sonhos relacionados ao trauma instigam uma "fixação" na vivência da situação que o desencadeia, isto é, uma reencenação da cena traumática. Desse modo, o neurótico seria aquele que sofre de uma "compulsão à repetição", no presente, do passado.

No decorrer do texto, no entanto, Freud opera um importante deslocamento conceitual: dispensa a repetição traumática do campo estritamente patológico. Nas palavras do autor, "o que a psicanálise aponta nos 
fenômenos de transferência dos neuróticos é encontrado igualmente na vida de pessoas não neuróticas" (FREUD, 2010a, 134). Tal mudança deriva da segunda tópica freudiana defendida em Além do princípio do prazer, que incide sobre o caráter dinâmico do aparelho psíquico. De acordo com ela, o consciente e inconsciente passam de categorias topográficas a processos pulsionais, que coexistem nas instâncias psíquicas humanas, como se percebe no seguinte trecho:

(...) somos instados a corrigir uma inadequação de nossa maneira de expressão. Evitaremos a falta de clareza se colocarmos em oposição não o consciente e o inconsciente, mas sim o Eu coerente e aquilo que é reprimido. Não há dúvida de que muito do Eu é em si mesmo inconsciente, justamente o que se pode chamar de âmago do Eu; apenas uma pequena parte dele é coberta pelo termo "pré-consciente" (ibidem, 132 - grifos em itálico do autor; em negrito, meus).

Pode-se notar assim que Freud passa a ampliar o escopo da repetição traumática, tornando-a um processo dinâmico normal da economia psíquica. Sob essa ótica, as fronteiras que separam e hierarquizam indivíduo sadio e enfermo se tornam mais fluidas.

Quase vinte anos depois do texto, Walter Benjamin, contemporâneo e leitor de Freud, recorre à psicanálise ao tentar dar conta da poética de Charles Baudelaire, que compreende como marcada pelo choque mnemônico em toda sua extensão. Conforme afirma Seligmann-Silva (2006, 49), o historiador faz um gesto análogo ao de Freud no âmbito da clínica, isto é, joga luz sobre o alargamento da experiência do choque, trazendo-o mais radicalmente ao âmbito cultural: "Para Benjamin, o choque é parte integrante da vida moderna: a experiência agora deixa de submeter-se a uma ordem contínua e passa a estruturar-se a partir das inúmeras 'interrupções' que constituem o cotidiano moderno".

A propósito do alargamento dos limites entre normalidade e exceção do choque na produção artística da época, Benjamin $(2000,110)$ chega a questionar frontalmente: "de que modo a poesia lírica poderia estar fundamentada em uma experiência, para qual o choque se tornou a norma?". No que toca a fotografia e o cinema, o autor faz o elogio tecnológico do trauma, fazendo ele mesmo referência ao discurso psicanalítico para tal. Em $A$ obra na era de sua reprodutibilidade técnica, lê-se: "(...) a câmara com seus inúmeros recursos (ECO-UFRJ) e graduada em Rádio e TV (ECO-UFRJ). Brasileira, Rio de Janeiro - RJ. E-mail: 
auxiliares, suas imersões e emersões, suas interrupções e seus isolamentos, suas extensões e suas acelerações (...). Ela nos abre, pela primeira vez, a experiência do inconsciente ótico, do mesmo modo que a psicanálise nos abre a experiência do inconsciente pulsional (BENJAMIN, 1985, 189).

Diante disso, busca-se no presente trabalho compreender como o estudo da clínica psicanalítica pode orientar uma nova disposição em relação à história, que escape à mudez do choque e busque dar conta das demandas subjetivas e políticas colocadas sobretudo desde a destruição da guerra. Não à toa Seligmann-Silva aponta a crescente disseminação nos meios historiográficos de uma literatura do testemunho na segunda metade do século $X X$, que assume esta ambígua e árdua tarefa. O testemunho como modalidade discursiva predominante na contemporaneidade merece, portanto, especial atenção e pode oferecer pistas para construção de uma nova experiência histórica a partir da memória traumática.

\section{0 testemunho como modalidade discursiva}

Os afogados e os sobreviventes, do Primo Levi, Les assassins de la mémoire, de Pierre Vidal-Naquet, e a biografia do historiador Daniel Goldhagen, Daniel Jonah Goldhagen: pesquisa também como resposta a questões bem pessoais são conhecidos exemplos de relatos da vida nos campos de concentração nazistas. Escritos a partir da própria vivência ou da de familiares e amigos próximos, vítimas do Holocausto, tais obras são signatárias do que Seligmann-Silva chama de literatura do testemunho. Ao contrário do que a expressão indica, esses livros não surgiram apenas como gênero literário, mas abalaram os círculos intelectuais ao se proporem como fontes históricas, que evidenciavam o ocorrido durante o massacre.

De acordo com a filósofo e historiador Georges Didi-Huberman $(2008,20)$, esse episódio da guerra é marcado pela insuficiência de fontes oficiais que o comprovem, ao que se refere como "máquina de des-imaginação" nazista. O autor reproduz a fala registrada de um ex-oficial da SS, que afirma um esforço 
consciente de apagamento das evidências dos crimes perpetrados. Diante disso, o testemunho dos sobreviventes figura como uma das poucas fontes possíveis de comprovação do Holocausto.

Entretanto, o caráter mnemônico dos documentos incentivou uma onda revisionista na academia, que os rechaçava como peças de valor científico, passíveis de um estudo objetivo da história. Seligmann-Silva $(2006,66)$ resume a polêmica então colocada ao defender que, a partir daí, figura-se "uma dialética entre a memória e a História enquanto duas modalidades de relação com o passado". Pode-se, assim, destacar algumas características da narrativa memorial que se afastam da historiografia tradicional e que apontam novos caminhos rumo outras experiências da temporalidade moderna, afeitas ao choque.

A começar pela análise de Gagnebin, a memória traumática indica uma mudança na relação entre verdade e história, que passa a ser mais radicalmente atravessada por um caráter ficcional. Seligmann-Silva, por sua vez, se detém sobre a experiência pessoal, tomada como único indício possível de um fenômeno universal. Diante disso, pretende-se então aproximar tais aspectos do testemunho e as contribuições de Freud e Benjamin para a história de modo a situá-los contextualmente e explicá-los com maior justeza.

\section{Verdade, ficção e história}

A memória traumática como questão contemporânea, de acordo com Gagnebin (2009, 41), surge no seio de uma transformação paradigmática na concepção da história, ou "verdade do passado": esta deixa de se tratar de um "problema de adequação" entre narrativa e fato e passa a figurar como "ética da ação presente". Com isso, a autora critica o historicismo positivista o acusa de ter servido ao discurso fascista da guerra. Para tal, apoia-se na crítica também proposta por Benjamin acerca do assunto.

Em Sobre o conceito de história, o filósofo alinha a vitória do fascismo alemão à crença na temporalidade do progresso. Sobretudo na tese 13 , ele 
denuncia o dogmatismo dessa concepção, marcada pela falta de vínculo com a materialidade da história em nome de uma humanidade abstratamente almejada e infinitamente sustentável, o que resumiu como uma "marcha no interior de um tempo vazio e homogêneo". Em oposição a este, o autor reivindica um "tempo saturado de 'agoras", que faz "explodir o continuum da história", como "um salto de tigre em direção ao passado" (BENJAMIN, 1985, 229, 230). Haja vista que o futuro é o tempo da catástrofe progressista, Benjamin defende que o historiador deve, portanto, voltar-se ao passado. O passado benjaminiano, no entanto, também deve escapar dos perigos de um tempo homogêneo e vazio, redimindose apenas mediante demanda do presente. Isso porque "irrecuperável é cada imagem do passado que se dirige ao presente, sem que esse presente se sinta visado por ela (ibidem, 224).

De um modo geral, Benjamin propõe uma nova concepção de história que repudia as abstrações do idealismo fascista e se centra no trabalho ativo do historiador materialista. Há na obra do autor um alinhamento entre posicionamento político e ético diante das próprias narrativas, que se aproxima da concepção de verdade como "ética da ação presente" de Gagnebin. A literatura do testemunho, enquanto discurso da memória, pode ser, então, legitimada a partir da leitura benjaminiana. Entendendo a latência do choque traumático como uma imagem do presente que se lança em direção ao passado, é possível tomar os relatos testemunhais como obras de historiador, sobretudo diante da potência política disruptiva em relação às narrativas fascistas.

Enquanto Benjamin defende a importância da posição ética perante 0 problema da história, a trajetória da psicanálise freudiana pode oferecer pistas acerca da transição paradigmática da verdade. Em História de uma neurose infantil ou o homem dos lobos, nota-se que Freud adota uma postura absolutamente interpretativa do caso em questão, buscando estabelecer uma relação de adequação entre os sintomas apresentados pelo analisante e as cenas primárias de sua vida. Tal postura se torna manifesta no seguinte trecho:

Algo de novo se ganha apenas com as análises que oferecem dificuldades especiais, cuja superação requer muito tempo. Somente nesses casos conseguimos descer às camadas mais fundas e primitivas do desenvolvimento psíquico, lá encontrando as soluções Mestranda em Comunicação e Cultura, na linha Tecnologias da Comunicação e Estéticas (ECO-UFRJ) e graduada em Rádio e TV (ECO-UFRJ). Brasileira, Rio de Janeiro - RJ. E-mail: palomapalaciom@gmail.com. 
para os problemas das configurações posteriores. Dizemos então que, a rigor, somente a análise que vai tão longe merece este nome. Naturalmente um único caso não ensina tudo que se gostaria de saber. Mais precisamente, ele poderia ensinar tudo, se estivéssemos em condição de tudo apreender e não fôssemos obrigados, pela imperícia de nossa percepção, a nos satisfazer com pouco (FREUD, 2010b, 20, grifos meus).

É evidente, portanto, que, nessa época, o autor buscava atuar como médico cientista, no sentido positivista do termo: acreditava que o sofrimento do Homem dos lobos poderia ser solucionado pelo analista mediante um projeto longo e árduo de interpretação de seus signos mentais. Neste texto, Freud emprega expressões como "verdade histórica" para se opor às "fantasias" e às "lembranças encobridoras" do analisante, que produziam nele falsas imagens de sua própria história. A conexão causal entre as cenas primárias, alcançadas pela rememoração do passado, e a compulsão posterior delas decorrente, latentes no presente da análise, é um dos temas centrais da obra. Há um claro constrangimento do autor em assumir que as cenas infantis, mesmo que reais, são resultantes de uma "construção" fantasiosa (ibidem, 45); ao passo que defende a existência necessária de um nexo causal entre a neurose infantil e a adulta (ibidem, 88).

Desta breve análise, pode-se concluir que o Freud do Homem dos lobos apoiava o valor do tratamento psicanalítico na sua capacidade de resolver 0 problema de adequação entre palavra e fato histórico, tal qual o historicismo denunciado por Gagnebin. O que é mais, o psicanalista atribuía suma importância ao tempo da elaboração traumática. A memória deveria ser ativada apenas a partir das demandas do presente. O tempo a posteriori do trauma garante, assim, uma relação plural com o passado, incompatível com o paradigma da adequação.

Há, entretanto, uma profunda transformação paradigmática também em Freud a propósito da verdade, sobretudo a partir d'A Interpretação dos sonhos. Nesta obra, o autor se lança ainda a um trabalho descritivo das manifestações oníricas, tarefa essa que, por outro lado, não tem mais como horizonte a representação absoluta das imagens. O psicanalista defende o que chama de "umbigo do sonho". Sobre isso: 


\begin{abstract}
Mesmo no sonho mais minuciosamente interpretado, é frequente haver um trecho que tem de ser deixado na obscuridade; é que, durante o trabalho de interpretação, apercebemo-nos de que há nesse ponto um emaranhado de pensamentos oníricos que não se deixa desenredar e que, além disso, nada acrescenta a nosso conhecimento do conteúdo do sonho. Esse é o umbigo do sonho, o ponto onde ele mergulha no desconhecido. (...) Os pensamentos oníricos a que somos levados pela interpretação não podem, pela natureza das coisas, ter um fim definido; estão fadados a ramificar-se em todas as direções dentro da intricada rede de nosso mundo do pensamento. É de algum ponto em que essa trama é particularmente fechada que brota o desejo do sonho, tal como um cogumelo de seu micélio (FREUD, 1969, 125, grifos meus)
\end{abstract}

Dito de outro modo, o autor determina os limites do trabalho psicanalítico diante da sua própria empreitada. Este paradoxo atravessa as obras de Freud: em um de seus últimos escritos, Análise terminável e interminável, por exemplo, o tom apologético com que trata da impossibilidade de alcançar todos os objetivos da terapia psicanalítica predomina no texto.

Por sua vez, Michel Foucault (1997), ao se debruçar sobre a obra de Freud, nota um gesto comum entre o fundador da psicanálise, Nietzsche e Marx, no que toca a relação entre linguagem e história: o nascimento de uma hermenêutica. Segundo o pensador francês, esta é definida precisamente pelo "inacabado da interpretação". Já que não há mais um símbolo primeiro a que se remeter, a interpretação se torna uma tautologia, em que as palavras se referem apenas a si mesmas. Sendo assim, o tempo da hermenêutica é circular, e coloca em primeiro plano não mais o porquê de dizer, mas quem o diz - o único responsável por sua própria interpretação.

A análise foucaultiana da psicanálise foi um dos primeiros esforços intelectuais que visaram situá-la para além da tensão com a ciência médica. $O$ autor inseria o próprio pensamento na esteira da hermenêutica inaugurada por Freud, uma vez que seu método se baseava não mais na noção de verdade histórica, como passado a ser revelado. Ao contrário, afirmava uma história da verdade, traçada de inquietações latentes no presente do discurso. Em História da sexualidade, Foucault $(1988,122)$ empreende assim o que chamou de "arqueologia da psicanálise" - esta enquanto discurso singular sobre a verdade do sexo. De acordo com ele, quando Freud disserta sobre a interdição do incesto, por exemplo, propõe dois movimentos contraditórios. Por um lado, defende um movimento de normativização das práticas incestuosas, o que alinha

Mestranda em Comunicação e Cultura, na linha Tecnologias da Comunicação e Estéticas (ECO-UFRJ) e graduada em Rádio e TV (ECO-UFRJ). Brasileira, Rio de Janeiro - RJ. E-mail: palomapalaciom@gmail.com. 
o discurso psicanalítico a um poder que disciplina corpos ditos anormais. Por outro lado, aponta para uma repressão como dispositivo de ordem sexual assim como política, minando por fim a própria validade da norma.

A essa altura, torna-se mais palpável a mudança paradigmática de Gagnebin a propósito da história. A terapia freudiana foi responsável por colocar o problema da adequação e, paradoxalmente, lançar as bases da superação dessa concepção de verdade. A princípio, Freud busca a separação entre lembranças verdadeiras e fantasiosas de modo a operacionalizar o tratamento; ao admitir a irrepresentabilidade das dinâmicas inconscientes, afirma o caráter ambíguo da memória traumática. Gagnebin e Seligmann-Silva se referem a isso como um necessário caráter ficcional do testemunho histórico. Os escritos benjaminianos sobre a história orientam o deslocamento paradigmático em relação à verdade, negando a metafísica idealista dos fascistas e afirmando-a como compromisso ético do historiador inscrito no presente de sua enunciação.

\section{Entre o particular e o universal: paradoxo como paradigma da memória}

É preciso ainda discorrer sobre um aspecto singular da narrativa testemunhal, a que Seligmann-Silva $(2006,68,69)$ se refere como dialética entre uma perspectiva de "total objetividade", própria da história e uma de celebração do "elemento fragmentário da temporalidade, típico do registro pessoal ou coletivo da memória". Retomando a hermenêutica foucaultiana, pode-se dizer que há uma circularidade do discurso moderno a partir de Freud, que se dá pela afirmação da singularidade dos discursos. Embora essa apreciação possa encaminhar uma visão solipsista da linguagem e da memória, vale lembrar que tanto a psicanálise como a história benjaminiana buscaram articular o trabalho sobre o fragmento a um dever político. Afinal, uma vez que o problema da adequação se torna secundário, o caráter paradoxal dessa tarefa não tem mais por que ser resolvido.

Por conta disso, há autores que compreendem a tensão entre particular e universal, como Seligmann-Silva acerca do testemunho, ou entre privado e público, como Foucault acerca da sexualidade, enquanto um sintoma da modernidade. O pensamento do sociólogo alemão Andreas Huyssen (2014) 
acerca da relação entre o moderno e a memória vai ao encontro desta acepção. Segundo ele, a modernidade sempre foi marcada pela ambiguidade. Ele aponta, por exemplo, que "foi no modernismo clássico que o moderno ligou-se pela primeira vez ao não moderno, amiúde em termos de apropriação, mas sempre criticando a civilização burguesa e sua ideologia do progresso" (ibidem, 21). Dito de outra maneira, a modernidade tem por característica questionar o próprio tempo.

$\mathrm{Na}$ esfera da mediatização da cultura, o autor Jesús Martín-Barbero (2001) se debruça sobre a relação entre indivíduo e sociedade de massa, pauta essa que passou a dominar os meios intelectuais a partir do século XVII. Para o autor, Freud se insere nessa problemática ao buscar estabelecer uma paridade da dinâmica psíquica entre as duas instâncias, sobretudo no final de sua obra. Em Mal-estar da civilização, o psicanalista repete as noções de morte e vida, do âmbito individual, no político. Apresentadas em Além do princípio do prazer, tais forças anatagônicas atuam no indivíduo por ocasião da dinâmica entre prazer e desprazer no aparelho psíquico. Para cercar o que chamou de "narcisismos das pequenas diferenças", Freud afirma a co-presença de tais forças também na rivalidade entre comunidades vizinhas, como espanhóis e portugueses, ingleses e escoceses: "É sempre possível unir um considerável número de pessoas no amor, enquanto sobrarem outras pessoas para receberem as manifestações de sua agressividade" (FREUD, 2011, 72).

A partir dessa exposição, é possível construir dois argumentos que dialoguem com a questão apresentada. Primeiramente, as noções de forças de vida e de morte dizem respeito a um funcionamento paradoxal da psique a nível individual e cultural, ao que se pode arriscar uma aproximação com a dialética entre memória e história proposta a partir do testemunho. É precisamente sobre este paradoxo, ao que Freud se refere como mal-estar, que a civilização humana poderia ser erigida. Além disso, a articulação entre o âmbito privado e o interesse público sugere a possibilidade de uma gestão horizontal democrática da vida moderna, ao que Foucault (1988) chamou de síntese entre o dispositivo da sexualidade e o sistema de alianças. É dessa forma que o estudo da dinâmica psíquica entre prazer e desprazer pôde orientar uma política dos afetos.

Mestranda em Comunicação e Cultura, na linha Tecnologias da Comunicação e Estéticas (ECO-UFRJ) e graduada em Rádio e TV (ECO-UFRJ). Brasileira, Rio de Janeiro - RJ. E-mail: palomapalaciom@gmail.com. 
Benjamin (2009), por sua vez, se apoderou da alegoria do catador de lixo para propor à sua maneira uma dialética ao historiador materialista. Em referência à poesia lírica de Baudelaire, o autor descreve o ofício do artista como o de um colecionador de restos, cujo mérito reside exatamente na triagem dos "estilhaços" do passado que decide recolher. Diante deles, o trabalho de historiador deve se inspirar na artesania das narrações tradicionais, de forma a produzir uma montagem de tais fragmentos. Em oposição à história universal "homogênea e vazia", o autor faz um elogio messiânico do fragmento.

A construção de uma nova história, calcada na memória, se daria, portanto, de acordo com a temporalidade do choque, próprio tanto do trauma quanto da fotografia e do cinema: "O passado só se deixa fixar, como imagem que relampeja irreversivelmente, no momento em que é reconhecido". O trabalho de montagem do historiador, desse modo, pode ser equiparado ao trabalho de montagem cinematográfica. Não à toa, o cineasta francês Jean-Luc Godard $(1998,245)$ afirma que o cinema é a arte da montagem, num sentido redentor análogo ao de Benjamin: “(...) malgré tout au montage l'objet est vivant, tandis qu'au tournage il est mort. II faut le ressusciter. C'est de la sorcellerie”"

\section{CONCLUSÃO}

Pode-se dizer que o desenvolvimento da psicanálise em Freud e da concepção de história em Benjamin encontram na memória, enfim, uma temporalidade comum. Melhor dizendo, os dois autores encaminham a pesquisa de suas vidas de modo a se furtar da história linear. Sua potência consiste precisamente em seu caráter fragmentário, além de orientar uma nova posição ética diante do passado. Uma vez que a história se articula à memória, é o presente da rememoração que se dirige e inquire o passado traumático conforme as suas demandas.

\footnotetext{
${ }^{3}$ Tradução minha: Apesar de tudo, na montagem o objeto está vivo, enquanto que na filmagem ele está morto. É preciso fazê-lo ressuscitar. Essa é a mágica. 
Sendo assim, ela deixa de buscar espelhar os fatos ocorridos, mas reconstruí-los. Tal concepção dispensa a verossimilhança como paradigma, afirmando o paradoxo como principal aspecto dessa reconstrução. A psicanálise pode figurar na contemporaneidade, portanto, enquanto posição estratégica na invenção de uma resistência política, calcada numa temporalidade outra dos corpos na história. Paralelamente, o cinema moderno é atravessado pelo que Deleuze $(2005,50)$ se refere como imagem-cristal: "é preciso que a imagem seja presente e passada, ainda presente e já passada, a um só tempo, ao mesmo tempo", tal qual a dupla face de um cristal. Ao desafiar o tempo homogêneo da história, o cinema contemporâneo herda essa problemática, também podendo redesenhar os corpos sobre a tela. A temporalidade dos corpos desejantes se torna, assim, na psicanálise e no cinema, questão de montagem de uma nova história.

\section{REFERÊNCIAS}

BENJAMIN, W. Obras escolhidas I: Magia e técnica, arte e política. São Paulo: Brasiliense, 1985.

. Sobre alguns temas em Baudelaire. In: Obras escolhidas III: Charles Baudelaire: um lírico no auge do capitalismo. São Paulo:

Brasiliense, pp. 103-149.

. Teoria do conhecimento, teoria do progresso. In: Passagens. São Paulo: Imprensa Oficial de São Paulo, 2009.

DELEUZE, G. Os cristais de tempo. In: A imagem-tempo. São Paulo: Brasiliense, 2005.

DIDI-HUBERMAN, G. Images in spite of all. In: Images in spite of all. Chicago: University of Chicago Press, 2008, pp. 3-197

FOUCAULT, M. História da Sexualidade I: a vontade de saber. Rio de Janeiro: Edições Graal, 1988.

Nietzsche, Freud \& Marx. In: Nietzsche, Freud \& Marx Theatrum Philosoficum. Trad. Jorge Lima Barreto. São Paulo: Princípio, 1997. 
Universitária, 2008.

A arqueologia do saber. Rio de Janeiro: Forense

FREUD, S. A interpretação dos sonhos. In: Edição standard brasileira das obras psicológicas completas de S. Freud, J. Salomão, trad., Vol. 5. Rio de Janeiro: Imago, 1969.

Análise terminável e interminável. In: Edição standard brasileira das obras psicológicas completas de S. Freud, J. Salomão, trad., Vol. 23. Rio de Janeiro: Imago, 1996, p.135-164.

Além do princípio do prazer. In: Obras Completas de Sigmund Freud, Vol. 14. São Paulo: Cia das Letras, 2010a, pp. 120-178.

. História de uma neurose infantil. In: Obras Completas de Sigmund

Freud, Vol. 14. São Paulo: Cia das Letras, 2010b, pp. 9-119.

2011.

. O mal-estar na civilização. São Paulo: Penguin \& Cia das Letras,

GODARD, J.L. Le montage, la solitude et la liberte. In: Jean-Luc Godard par Jean-Luc Godard, tome 2 (1984- 1998). Cahiers du cinéma-éd. de l'Étoile, Paris, 1998, p. 242-248.

GAGNEBIN, J. Lembrar, escrever, esquecer. São Paulo: 34, 2009.

GATTI, L. Correspondências entre Benjamin e Adorno”. Revista Limiar.

Guarulhos, v. 1, n. 2, jan-jun. 2014. Acesso em:

http://www2.unifesp.br/revistas/limiar/pdf-nr2/05_Luciano-

Gatti_Correspondencias-entre-Benjamin-e-Adorno_Limiar_vol-2_nr-1_1-sem-

2014.pdf

HUYSSEN, A. Culturas do passado-presente: modernismos, artes visuais, políticas da memória. Rio de Janeiro: Contraponto, 2014.

MARTÍN-BARBERO, J. Nem povo nem classes: a sociedade de massas. In: Dos meios às mediações: comunicação, cultura e hegemonia. 2 ed. Rio de Janeiro: Editora da UFRJ, 2001.

SELIGMANN-SILVA, M. Apresentação da questão: a literatura do trauma. In: SELIGMANN-SILVA, M. (Org.). História, memória, literatura: o testemunho na era das catástrofes. Campinas: Unicamp, 2006. p. 45-88. 